\title{
Análisis tecno-morfológico y morfológico-funcional de los conjuntos líticos tallados del sitio El Remate (Amaicha del Valle, Tucumán)
}

Flavia M. Germano*

\section{Resumen}

En este trabajo se presenta el análisis tecno-morfológico y morfológico-funcional de los conjuntos líticos procedentes de una transecta de recolección superficial y de las excavaciones de un recinto habitacional del sitio El Remate (Amaicha del Valle, Tucumán). Dataciones por AMS permitieron establecer dos ocupaciones para el sitio (900 años AP y 1130 años AP). El objetivo es establecer la secuencia de producción lítica desarrollada por los grupos que habitaron el área, definir las diferentes actividades tecnológicas y analizar aspectos relacionados con la obtención y uso de las materias primas de acuerdo a la disponibilidad y accesibilidad de las mismas. Los datos obtenidos nos permiten plantear el predominio del uso de materias primas locales para la confección de instrumentos y la presencia de todas las etapas de la secuencia de producción en el sitio. Esto constituye un importante aporte para el conocimiento de la tecnología lítica del período Formativo en los valles.

\section{Techno-morphological and morpho-functional analysis of the lithic assemblages from El Remate site (Amaicha del Valle, Tucumán)}

\begin{abstract}
In this article, we present the techno-morphological and morphological-functional analysis of the lithic assemblages from a surface collection transect, and the excavations of a housing enclosure at El Remate site (Amaicha del Valle, Tucumán). AMS dates suggest two occupations for the site (900 years BP and 1130 years BP). Our aim is to establish the lithic production sequence developed by the groups that inhabited the site, define the different technological activities, and analyze trends related to the procurement and use of raw materials according to its availability and accessibility. The data obtained allowed us to suggest that there was a predominant use of local raw materials in the manufacture of instruments, and the presence of all production sequence stages on site. In turn, this is an important contribution to lithic technology knowledge for the Formative period in these valleys.
\end{abstract}

Recibido: 31 de marzo de 2017

Aceptado: 26 de agosto de 2017

\section{Palabras clave}

Tecnología lítica Secuencia de producción Amaicha del Valle

\section{Keywords}

Lithic technology Production sequence Amaicha del Valle

* Instituto Superior de Estudios Sociales (ISES), Facultad de Ciencias Naturales e Instituto Miguel Lillo, Universidad Nacional de Tucumán (UNT) - CONICET. San Martín 1545 (CP T40ooCWE), San Miguel de Tucumán, Tucumán, Argentina. E-mail: germanoflaviam@gmail.com 


\section{Introducción}

En este trabajo se presenta el análisis de los conjuntos de artefactos líticos tallados recuperados en contextos agropastoriles, datados entre 1130 y 900 años AP en El Remate, Amaicha del Valle, Tucumán. La tecnología lítica del período Formativo en los valles ha tomado mayor interés entre los investigadores durante los últimos diez años (Carbonelli, 2012; Hocsman, Somonte, Babot, Martel y Toselli, 2003; Lazzari, 1998; Oliszewski, 2011; Somonte, 2007, 2009). Los antecedentes arqueológicos de Amaicha del Valle y de valles aledaños, relacionados específicamente con tecnología, muestran que la producción lítica en los distintos sitios adquirió ciertas particularidades en función de los emplazamientos, la funcionalidad de los sitios y la cronología (Cigliano, 1960, 1961, 1962, 1968; García Salemi y Durando, 1985; García Salemi, Platanía y Durando, 1988; Somonte 2005, 2007, 2009; Somonte y Baied, 2011, 2013; entre otros). En general los sitios evidencian estrategias de aprovisionamiento con predominio de materias primas locales, dada su accesibilidad y disponibilidad en fuentes secundarias, explotación diferencial de las materias primas y procesos de reclamación evidenciados a través de las pátinas (Somonte, 2007; Somonte y Baied, 2011). Estas características fueron registradas en sitios formativos de la localidad arqueológica de Amaicha del Valle como Bajo los Cardones, Campo Blanco (Hocsman, et al., 2003; Somonte, 2002; Somonte, Hocsman, Martel y Babot, 2004) y zonas aledañas como el Valle de Yocavil (Carbonelli, 2011, 2012), El Divisadero en Ampimpa (Gómez Augier y Caria, 2012) y Quebrada de los Corrales (Martínez, Mauri, Mercuri, Caria y Oliszewski, 2013; Oliszewski, 2011; Oliszewski, Martínez y Caria, 2008). En líneas generales El Remate comparte ciertas características con sitios como Bajo los Cardones y Campo Blanco (algunas como cronología, disposición arquitectónica, alfarería) (Aschero y Ribotta, 2007) pero no hay mayor conocimiento sobre tecnología lítica en esta área. En este contexto el objetivo de este trabajo es establecer la secuencia de producción lítica desarrollada por los grupos que habitaron El Remate, definir las diferentes actividades tecnológicas y analizar aspectos relacionados con la obtención y uso de las materias primas de acuerdo a la disponibilidad y accesibilidad de las mismas, para aportar nuevos conocimientos sobre la funcionalidad de estos sitios de Amaicha del Valle.

Para llevar a cabo este objetivo tomamos el concepto de Torrence (1989a, p. 58) quien define a la tecnología lítica como un componente importante del comportamiento humano, por lo que "(...) entender la variabilidad en la forma de producción, uso, mantenimiento o el descarte de los instrumentos es explorar el papel de la tecnología como una de las estrategias de comportamiento alternativas". La autora concibe la tecnología como parte de un conjunto más amplio de comportamientos dentro del cual cobra sentido (Torrence, 1989a). Esto conduce a plantear el análisis de la producción de artefactos líticos como una forma de obtener información acerca de un amplio rango de conductas de subsistencia y comportamientos sociales en general. Otro de los conceptos importantes es el de secuencia de producción ya que comprende las distintas etapas de manufactura que fueron seguidas para producir un artefacto de un determinado tipo de diseño y en una determinada clase de roca (Aschero, 1988). Este toma en cuenta el proceso que va desde la obtención de la materia prima, hasta el mantenimiento del diseño particular de cada filo o punta formatizada del artefacto, abarcando la etapa de extracción de formas base y su formatización. La aplicación de este concepto no incluye la definición de usos ni tampoco la de modalidades técnicas específicas de producción de los distintos artefactos, percusión, presión, etc. Pero aún con estas restricciones es un concepto instrumental importante para observar la interrelación, en un sitio o nivel, entre distintas clases de artefactos de una misma materia prima y obtener información válida para definir aspectos de un sistema de producción lítica (Aschero, Moya, Sotelos y Martínez, 1995; Ericson, 1984). 


\section{El sitio}

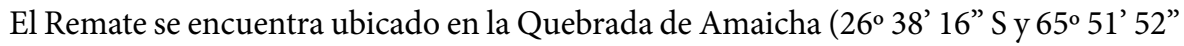
O), en el piedemonte de las Sierras del Aconquija, localidad de Los Zazos, Provincia de Tucumán (Figura 1). A $2.300 \mathrm{~m}$ s.n.m. sobre una altiplanicie con pendiente SudesteNoroeste, se encuentra bordeado por barrancos en sus límites norte, este y oeste. Cuenta con acceso a diversos recursos tales como proximidad al río Amaicha, disponibilidad de materias primas líticas importantes para la construcción de viviendas e instrumentos y disponibilidad de fuentes de arcilla para la manufactura cerámica. En toda el área se registraron estructuras residenciales formadas por un recinto circular mayor o patio central de 7 a 10 metros de diámetro, con recintos subcirculares menores adosados a este y andenes de cultivo que en algunos casos se articulan a las unidades mayores (Aschero y Ribotta, 2007).

Dataciones sobre huesos de Camelidae recuperados en diferentes niveles de un recinto excavado arrojaron los siguientes fechados: (AMS UGA 8360) $1130 \pm 40$ años AP del nivel 12 a unos $65 \mathrm{~cm}$ de profundidad perteneciente a la ocupación más antigua; (AMS UGA 8360) $1180 \pm 40$ años AP en el nivel 10 a $55 \mathrm{~cm}$ de profundidad y (AMS UGA 8359) $900 \pm 40$ años AP para la última ocupación que correspondería al nivel 6, con una profundidad de $40 \mathrm{~cm}$ (Aschero y Ribotta, 2007).

Es importante conocer la disponibilidad y el área de procedencia de las materias primas a partir de las cuales se confeccionaron los instrumentos. En este trabajo fueron considerados como locales todos aquellos recursos disponibles a no más de $20 \mathrm{~km}$ y como no locales aquellas materias primas procedentes de una distancia que supera los $20 \mathrm{~km}$.

Dentro de los materiales recuperados en el sitio, las rocas volcánicas constituyen uno de los más utilizados como materias primas. Éstas provendrían del denominado Complejo Volcánico Portezuelo de las Ánimas, que corresponde a las rocas volcánicas de Sierras del Aconquija ubicadas a 3.600 y $4.384 \mathrm{~m}$ s.n.m. Estas rocas se encuentran presentes en el curso del río Los Corrales, que vierte sus aguas en el río Amaicha. El cauce de estos ríos posee clastos de tamaño variado, desde grandes bloques, que son los más frecuentes, hasta clastos muy pequeños (González, 1990). Las rocas volcánicas también están disponibles en el Valle de Santa María provenientes del Complejo Portezuelo de las Ánimas. Éstas forman parte del ciclo terciario del grupo Santa María (conglomerados, abundantes clastos y rodados de diversas vulcanitas). Estas unidades además ofrecen otros recursos importantes para la talla como es el caso del cuarzo cristalino y lechoso de la Formación Andalhualá y de la Formación Yasyamayo (González, 1990; González y Barreñada, 1993). Otros recursos líticos son los materiales cenoglomerádicos del cuaternario, de origen metamórfico disponibles en los abanicos de la vertiente occidental de Cumbres Calchaquíes y en el cauce del río Amaicha (Somonte y Baied, 2011).

En Amaicha del Valle las principales fuentes de aprovisionamiento de materias primas son de tipo secundaria y terciaria (Church, 1994), debido a que no existen afloramientos de roca in situ. Las andesitas de tipo B o basandesita, G y P y el cuarzo, que son los más comunes, se los encuentra en forma de rodados en fuentes secundarias. La fuente más importante es el río Amaicha, afluente del río Los Corrales, ambos relacionados a la formación Los Corrales y al Complejo Volcánico Portezuelo de las Ánimas (Somonte y Baied, 2011).

\section{Metodología}

Los conjuntos líticos analizados provienen, por un lado, de una transecta de recolección superficial (T1) de $10 \mathrm{~m}$ de frente por $190 \mathrm{~m}$ de longitud, con rumbo $329^{\circ}$ 

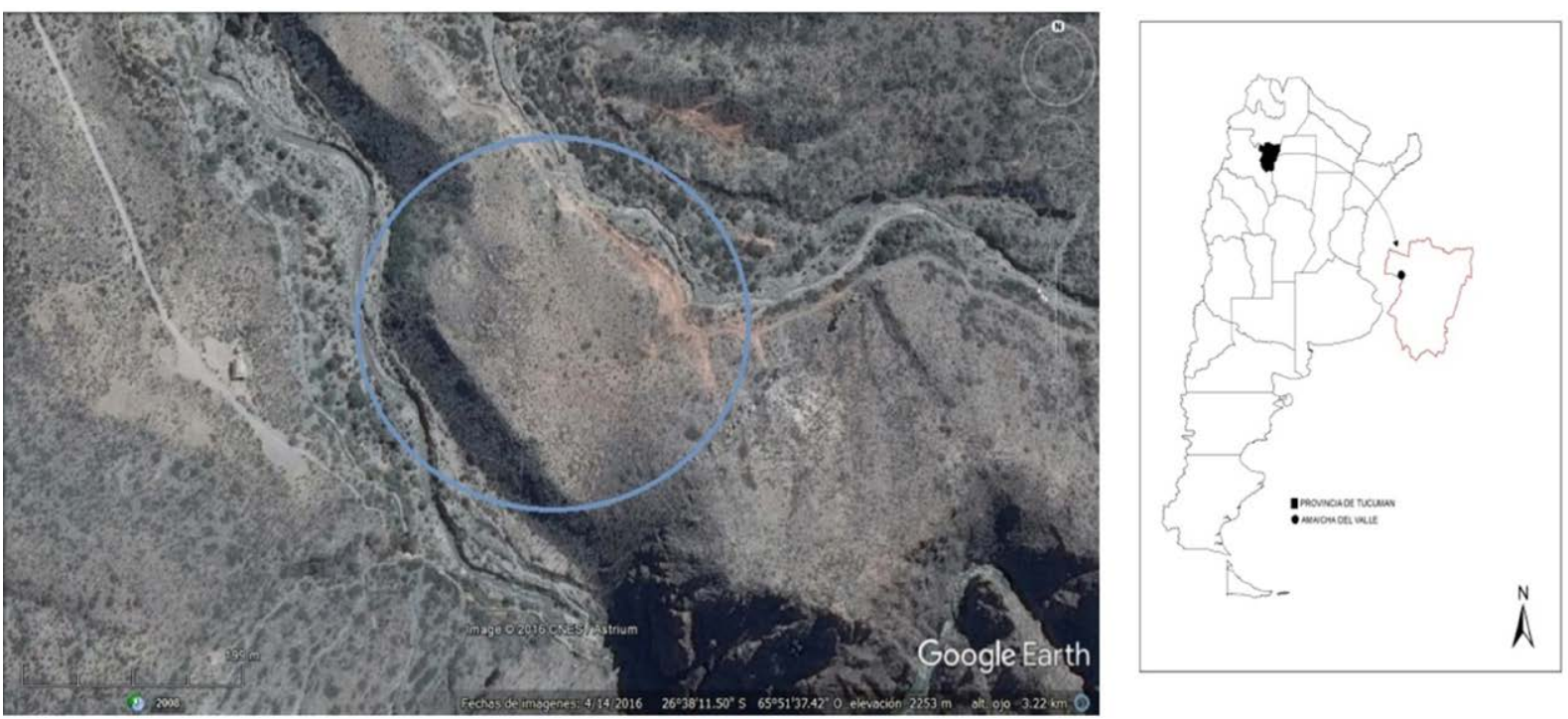

Figura 1. Vista aérea del sitio arqueológico El Remate.

Norte-Noroeste y de las excavaciones del recinto habitacional E49 (Figura 2), ubicado en el sector sur del sitio. En ambos casos la muestra está integrada por artefactos formatizados $(\mathrm{AF})$, núcleos $(\mathrm{N})$, desechos de talla $(\mathrm{DT})$ y filos naturales con rastros complementarios (FNRC).

El análisis tecno-morfológico y morfológico-funcional se realizó siguiendo la propuesta de Aschero $(1975,1983)$ y Aschero y Hocsman (2004). En primer lugar se segmentó por materia prima y luego por clases tipológicas. En todas las clases se tuvieron en cuenta variables y atributos relevantes para cumplir con los objetivos de este trabajo.

Entre las variables generales a ser consideradas, la materia prima se tuvo en cuenta en primer lugar ya que ésta permite conocer su uso diferencial de acuerdo con las características que presenta, como ser la calidad ofrecida para desarrollar actividades de talla, disponibilidad, accesibilidad y distancia a las fuentes. Además brinda información sobre las estrategias tecnológicas utilizadas, que van a depender de los costos de obtención de las mismas. El estado de fragmentación fue considerado en todas las clases tipológicas ya que ofrece información tecnológica relacionada con el uso de los artefactos en general.

Las dimensiones (longitud y anchura) colaboran al momento de realizar inferencias acerca de algunas características en lo que refiere a la producción, tratamiento de núcleos, artefactos formatizados y desechos de talla, es decir, realizar aproximaciones tendientes a evaluar las posibles etapas dentro de la secuencia de producción lítica. La forma base, tipo de lasca y origen de las extracciones informan acerca de aspectos tecnológicos que nos permiten relacionar a la tecnología lítica con cuestiones tales como la disponibilidad y accesibilidad de las materias primas como así también con las etapas de la secuencia de producción y la búsqueda de determinados tipos de formas base.

Las propiedades de los talones nos brindan información acerca de procesos de manufactura y advierte acerca de la preparación, o no, de plataformas de percusión para la extracción de determinados tipos de formas base como así también, sobre las técnicas de talla que fueron empleadas (Espinosa, 1995). Para tal fin, es importante además tener en cuenta algunos atributos asociados al talón, como ser: estado del 


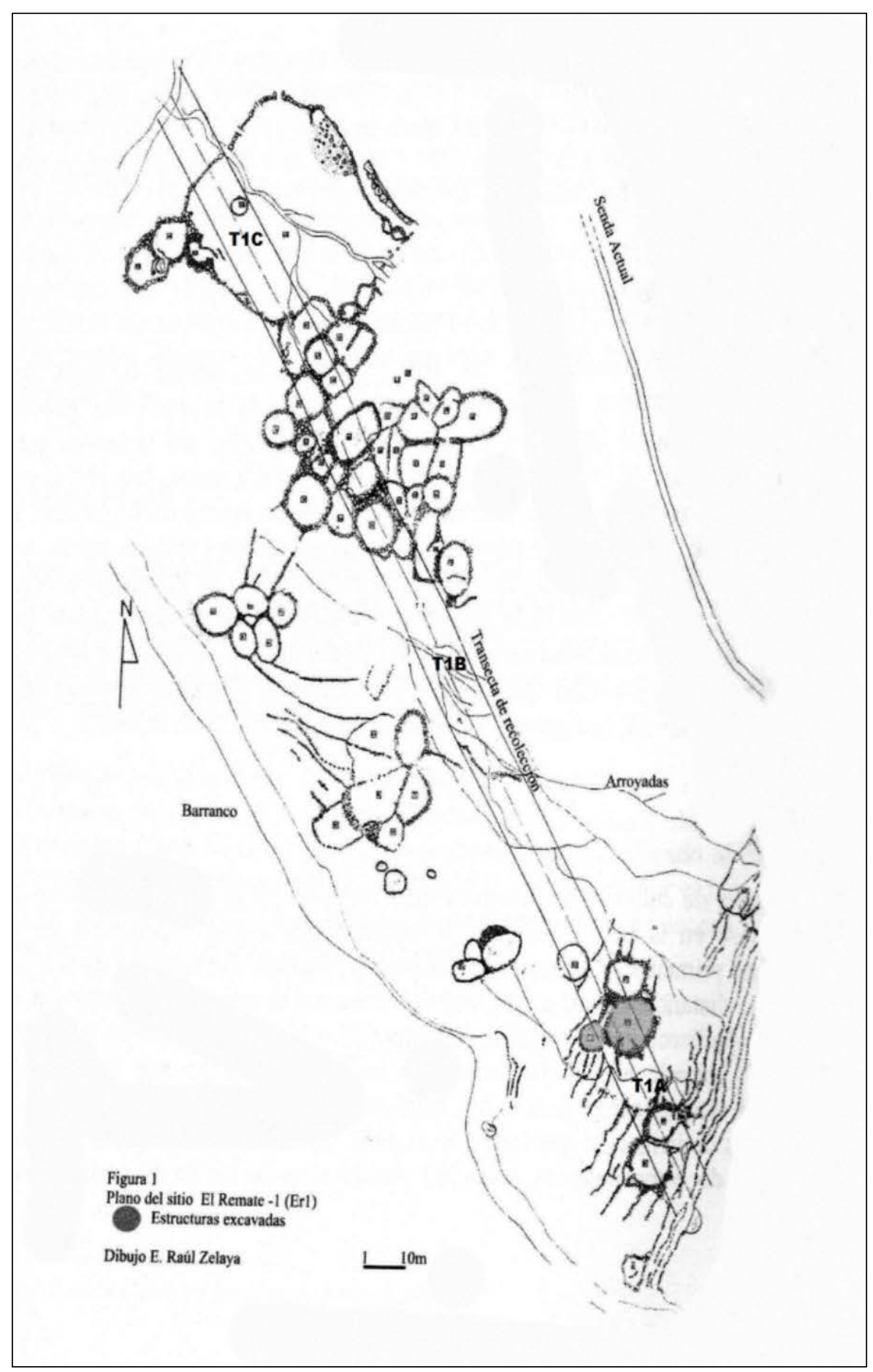

Figura 2. Croquis de la transecta de recolección y ubicación de E49.

talón, forma de la superficie del talón y regularización del frente de extracción. El bulbo de percusión y otros atributos asociados a la cara ventral como ser labio, estrías y ondas de percusión, también permiten realizar inferencias acerca de los tipos de talla representados en la muestra.

Por otro lado, para el análisis de los artefactos formatizados se tuvieron en cuenta la cantidad de filos y la combinación con grupos complementarios, a fin de contabilizarlos. 
Los artefactos compuestos presentan dos o más especímenes morfológicos pertenecientes a grupos tipológicos diferentes, en una misma unidad (Aschero, 1975). Esto permite evaluar el aprovechamiento y maximización de la materia prima. La serie técnica, determina los caracteres morfológicos que van a incidir en la regularización de las diferentes partes de una forma base. Entre los caracteres morfológicos que inciden en la regularización del filo se consideran el ancho de los lascados sobre el borde la pieza y la extensión de los lascados sobre las caras. Por otra parte, la situación de los lascados sobre las caras sirve para evaluar las técnicas de talla empleadas, distinguiendo el uso de la talla unifacial de la bifacial. El estado del filo, en relación a otras variables, permite evaluar el remanente de vida útil de los artefactos formatizados. La presencia o ausencia de corteza en los conjuntos líticos permite establecer la relación entre las tareas de reducción de núcleos, descortezamiento y la distancia a las fuentes de aprovisionamiento.

\section{Resultados}

La muestra total analizada consta de un total de 1.158 artefactos líticos repartidos en: 39 artefactos formatizados (AF), $43 \mathrm{~N}, 11$ filos naturales con rastros complementarios (FNRC) y 1.065 desechos de talla (DT). A continuación se presentan los resultados obtenidos procedentes por un lado del muestreo estratigráfico en E49 y por otro del muestreo superficial de T1.

\section{Presentación de la muestra del recinto E49}

El conjunto lítico recuperado en las excavaciones del recinto E49 está conformado por un total de 436 artefactos líticos y se presentan en la Tabla 1 según materias primas y clases tipológicas. Es importante dejar claro que los niveles de excavación correspondientes a la ocupación más temprana presentaron mayor densidad artefactual en comparación con los niveles superiores, pero los conjuntos artefactuales en todos los niveles presentan las mismas características. Por este motivo se presentan los resultados del interior del recinto como una unidad dado que, además, presentan un rango temporal similar y acotado.

La Tabla 1 muestra el predominio de desechos de talla, con el 93\%, sobre el resto (instrumentos, FNRC y núcleos) que suma el 7\% restante. Aproximadamente el 96\% corresponde a materias primas locales, sobresaliendo el uso de andesita B representando casi el $35 \%$, seguida por andesita G con el 33\% y el cuarzo con el 23\%, siendo menos representativa la andesita $\mathrm{P}(5 \%)$. Es casi nula la presencia de la materia prima no local, cuarcita y obsidiana, estando representada en menos del $2 \%$. El grupo de materias primas "No Determinadas" se relaciona con artefactos completamente afectados por calcretes, motivo por el cual fue imposible su correcta identificación.

El predominio de materias primas locales, especialmente andesita B y G, estaría indicando un uso diferencial de las mismas por parte de los grupos humanos. Esto se debe a la disponibilidad en fuentes secundarias cercanas al sitio. Las andesitas en general son accesibles a una distancia que no supera los $500 \mathrm{~m}$. En el río Amaicha abunda fundamentalmente la variedad de andesita G, y en menor proporción las $\mathrm{B}, \mathrm{P}$ y cuarzo, todas disponibles en forma de nódulos rodados, distribuidos a lo largo del cauce (Somonte, 2009). En cuanto a la calidad de las materias primas, en base a ciertas características físicas de las rocas propuestas por Nami (1992), se considera que la andesita B sería uno de los recursos que mejores cualidades ofrecerían para la talla, al igual que la obsidiana, la cual encontramos en menor proporción en el sitio y cuya obtención implicaría costos de aprovisionamiento marcadamente diferentes. 


\begin{tabular}{|l|c|c|c|c|c|c|c|c|c|c|}
\hline \multirow{2}{*}{ Materia Prima } & \multicolumn{2}{|c|}{ Núcleos } & \multicolumn{2}{c|}{ Desechos de talla } & \multicolumn{2}{c|}{$\begin{array}{c}\text { Filos naturales } \\
\text { con rastros } \\
\text { complementarios }\end{array}$} & \multicolumn{2}{c|}{ Instrumentos } & \multicolumn{2}{c|}{$\begin{array}{c}\text { Total por materia } \\
\text { prima }\end{array}$} \\
\cline { 2 - 12 } & $\mathbf{N}$ & $\%$ & $\mathbf{N}$ & $\%$ & $\mathbf{N}$ & $\%$ & $\mathbf{N}$ & $\%$ & $\mathbf{N}$ & $\%$ \\
\hline Andesita G & 7 & 1,60 & 130 & 29,81 & 1 & 0,22 & 7 & 1,60 & 145 & 33,23 \\
Andesita P & 0 & 0 & 25 & 5,73 & 0 & 0 & 0 & 0 & 25 & 5,73 \\
Andesita B & 5 & 1,14 & 144 & 33,02 & 1 & 0,22 & 2 & 0,45 & 152 & 35,13 \\
Cuarcita & 1 & 0,22 & 4 & 0,91 & 0 & 0 & 1 & 0,22 & 6 & 1,53 \\
Cuarzo & 0 & 0 & 102 & 23,30 & 0 & 0 & 1 & 0,22 & 103 & 23,52 \\
Obsidiana & 0 & 0 & 1 & 0,22 & 1 & 0,22 & 0 & 0 & 2 & 0,44 \\
No determinada & 0 & 0 & 3 & 0,68 & 0 & 0 & 0 & 0 & 3 & 0,68 \\
\hline $\begin{array}{l}\text { Total por clase } \\
\text { tipológica }\end{array}$ & $\mathbf{1 3}$ & $\mathbf{2 , 9 6}$ & $\mathbf{4 0 9}$ & $\mathbf{9 3 , 6 7}$ & $\mathbf{3}$ & $\mathbf{0 , 6 6}$ & $\mathbf{1 1}$ & $\mathbf{2 , 4 9}$ & $\mathbf{4 3 6}$ & $\mathbf{1 0 0}$ \\
\hline
\end{tabular}

Tabla 1. Distribución de artefactos líticos del recinto E49 según clase tipológica y materias primas.

\section{Núcleos}

Los núcleos $(\mathrm{n}=13)$ corresponden al $3 \%$ del total de la muestra de artefactos líticos. Entre estos predominan las andesitas en general, con un $93 \%$ de representatividad, que se reparte entre la G (54\%) y B (39\%). El 7\% restante se encuentra asociado a la cuarcita, recurso no local.

La muestra se compone de cuatro núcleos de tipo poliédricos (PO), cuatro con lascados aislados (CLA) y cinco fragmentos de núcleos no diferenciados (FNDN). La andesita $\mathrm{G}$ es la materia prima más representada. La andesita B cuenta con núcleos con lascados aislados y fragmentos. En cuarcita solo encontramos un núcleo poliédrico con numerosas plataformas de extracción. En relación al tamaño más del 75\% de los núcleos responden a las dimensiones de tamaños grande, muy grande y grandísimo y el $23 \%$ restante corresponde a núcleos de tamaño mediano pequeño.

\section{Desechos de talla}

Los desechos de talla suman un total de 409 que corresponden al 91\% de la muestra. El 98\% de los mismos corresponden a las materias primas locales y el 2\% restante está representado por materias primas no locales, cuarcita y obsidiana. El total de desechos de andesita es de 299 , es decir un $73 \%$ del total con un predominio de la variedad B en un $35 \%$, a la que le sigue la $\mathrm{G}$ con un $31 \%$ y, en menor proporción, la $\mathrm{P}$ con un $6 \%$. El cuarzo en este caso tiene una importante representatividad en la muestra ya que tiene un total de 102 desechos que corresponden al $25 \%$.

En cuanto al estado de fragmentación se destaca la marcada representatividad de los desechos fracturados (lascas fracturadas con y sin talón) (71\%), seguido por los desechos enteros (23\%) y por ultimo lascas indiferenciadas (5\%).

Es interesante destacar que los desechos enteros y/o fracturados estarían relacionados con determinadas actividades de la secuencia de producción lítica (Sullivan y Rozen, 1985). Estos autores sostienen que durante la manufactura y/o formatización de instrumentos se produce una mayor producción de lascas fracturadas (FCT y FST); mientras que durante la reducción de núcleos se obtiene una mayor cantidad de lascas enteras e indiferenciadas. En E49 cerca del 70\% de la muestra $(n=292)$ corresponde a lascas fracturadas, mientras que el $30 \%$ restante $(n=117)$ a lascas enteras 
e indiferenciadas. Esto estaría sugiriendo la realización de ambos tipos de actividades, aunque con un predominio de manufactura y/o formatización.

Para el análisis del origen de las extracciones se tuvieron en cuenta solo lascas enteras y lascas fracturadas con talón $(n=225)$. Esta variable es importante para poder definir qué actividades de la secuencia de producción se llevaron a cabo en este recinto. En la muestra predominan lascas internas en un $83 \%(n=187)$ sobre el total $(n=225)$, en su mayoría andesita $\mathrm{G}$ con un 33\%. En este punto es importante destacar que de 187 lascas internas, 138 son angulares, es decir que estas lascas estarían representando el 75\% del total. Las lascas internas resultan de procedimientos de extracción de formas base y formatización (reducción secundaria: retalla, retoque). Siguen en representatividad las lascas externas con un $16 \%$, siendo en este caso el cuarzo la materia prima más utilizada con un $6 \%$ resultando de tareas extracción primaria. Es llamativo esto, teniendo en cuenta la ausencia de núcleos de cuarzo en este sector del sitio dada la proximidad a la fuente de aprovisionamiento. Las lascas de adelgazamiento bifacial poseen una muy baja frecuencia en el registro lítico lo que se traduciría en un escaso énfasis en la realización de estas tareas. Esto posee claros correlatos con los tipos de artefactos formatizados presentes. Las tareas de reactivación de núcleos no parecen haber sido significativas en este caso ya que no se encuentran representadas en la muestra, aspecto que estaría relacionado con la cercanía a las fuentes.

Por otro lado, para definir el tamaño y el módulo longitud-anchura solo se consideraron lascas enteras, con el fin de evitar todo tipo de distorsión en las interpretaciones. Predominan tamaños medianos grandes en un 34\%, seguido por medianos pequeños con el $30 \%$. En frecuencia menor, encontramos presentes pequeños $18 \%$, grandes $16 \%$ y muy grandes en un $2 \%$. Solo dos desechos corresponden a cuarcita y sus tamaños son mediano pequeño y mediano grande.

En relación con el módulo longitud-anchura los predominantes en la muestra corresponden a los mediano normal, seguido por los cortos anchos y en tercer lugar medianos alargados. A partir de los datos relacionados con esta variable debe destacarse la presencia, en esta clase tipológica, de potenciales formas base para la confección de instrumentos.

Por otro lado, teniendo en cuenta que el talón y sus atributos pueden ayudar a clarificar la situación sobre los procesos de producción y técnicas implementadas se analizaron diferentes tipos de talones en la muestra de lascas enteras y fracturadas con talón. Predominan los talones preparados, con un $85 \%$ de representatividad destacándose la presencia de talones lisos sobre los demás, mientras que el $15 \%$ restante representaría talones corticales.

\section{Instrumentos}

Los instrumentos suman 11 y conforman el 2,49\% de la muestra total de materiales correspondientes a esta estructura. Muestran un predominio de andesita G como materia prima, con un $70 \%$ de representatividad sobre las restantes. La materia prima no local en este caso es la cuarcita, representada solo en un ejemplar. Es llamativa la ausencia de la andesita $\mathrm{P}$ teniendo en cuenta los desechos recuperados en ese tipo de recurso. Este comentario se hace extensivo a la obsidiana.

El estado de fragmentación indica que, del total de instrumentos, cinco se encuentran enteros y seis fracturados. Es importante dejar claro que para el análisis fueron considerados todos los instrumentos debido a que las fracturas no afectan las dimensiones por ser mínimas. 
Las variables tamaño y módulo fueron consideradas debido a su importancia al momento de comparar con los tamaños de lascas y los negativos de lascado de las últimas extracciones de los núcleos. El 85\% de los instrumentos tienen tamaño grande. Si relacionamos esto con el estado de fragmentación de los instrumentos podemos decir que, si bien seis de los 11 instrumentos se encuentran fracturados, estas fracturas no afectaron las dimensiones de las piezas. La distribución del módulo indica que el 45\% de los instrumentos responden a la categoría mediano normal. En segundo lugar se encontrarían los módulos corto ancho y corto muy ancho con el $18 \%$ cada uno. Las formas base predominantes son lascas internas (64\%), puntualmente lascas angulares. En los grupos tipológicos predominan los denticulados y artefactos de formatización sumaria en un $70 \%$, mientras que el $30 \%$ restante se distribuye entre una muesca retocada, un cuchillo de filo retocado y una punta de proyectil. De la muestra total de artefactos solo dos pertenecen al grupo de los compuestos y corresponde a dos denticulados que combinan con una formatización sumaria cada uno (Tabla 2, Figura 3).

Con respecto a la serie técnica, el $90 \%$ de los artefactos fueron formatizados por retoque marginal, con lo cual podemos decir que los instrumentos fueron confeccionados con una baja inversión de trabajo. Es importante hacer mención aparte de la punta de proyectil manufacturada sobre cuarcita que, como dijimos, pertenece a la materia prima no local. Se trata de una punta de proyectil apedunculada, de limbo triangular y base escotada, confeccionada con técnica de presión mediante retoques extendidos. Esta pieza presenta una pequeña fractura en su ápice y evidencias de mantenimiento. La forma base es indiferenciada, debido a los lascados de formatización que cubrieron completamente las caras. El tamaño es pequeño y tiene un módulo de longitud anchura laminar normal.

Para concluir podemos decir que hay baja inversión de trabajo en los instrumentos evidenciada por la presencia de piezas unifaciales con retoque marginal a excepción de la punta de proyectil, la cual, además de presentar mayor inversión de trabajo, fue confeccionada sobre materia prima no local.

\section{Filos naturales con rastros complementarios (FNRC)}

Se recuperaron tres FNRC, dos corresponden a andesita G y B y el tercero a obsidiana. El tipo de lasca en los tres casos es angular y el estado de fragmentación corresponde a una lasca entera (andesita G) y dos fracturadas con talón, con tamaños medianos grandes en los tres casos.

\section{Presentación de la muestra de recolección superficial}

El conjunto lítico recuperado en los sectores T1A y T1C de la transecta de recolección superficial está conformado por un total de 721 artefactos líticos. En la tabla 3 se presentan los artefactos según clases tipológicas y materia prima.

Aquí predominan desechos de talla, con más del 90\%, sobre las demás categorías (instrumentos filos naturales con rastros complementarios y núcleos) que suman el 9\% restante. En este caso, el 99\% del total de la muestra analizada corresponde a materias primas locales, sobresaliendo el uso de andesita $\mathrm{G}$ con casi el 50\%, le sigue la B con el $34 \%$, el cuarzo con el 9\% y en menor proporción la andesita P con un 5\%. Es casi nula la presencia de materias primas no locales (cuarcitas, sílice y obsidiana), las cuales que representan el $1 \%$. En este caso observamos la presencia de sílice (materia prima no local) y metamorfitas (recurso local) que no aparecían en la muestra anterior. Esto aumenta el espectro de recursos líticos utilizados en el sitio El Remate en general, mostrando mayor variabilidad de lo que se observaba a partir de la muestra del recinto E49. 


\begin{tabular}{|l|c|c|c|c|c|}
\hline Grupo tipológico & Andesita G & Andesita B & Cuarzo & Cuarcita & Total general \\
\hline Denticulado & 3 & 1 & 1 & 0 & 5 \\
Muesca retocada & 1 & 0 & 0 & 0 & $\mathbf{1}$ \\
Cuchillo de filo retocado & 1 & 0 & 0 & 0 & $\mathbf{1}$ \\
Punta de proyectil & 0 & 0 & 0 & 1 & $\mathbf{1}$ \\
Artefacto con formatización sumaria & 2 & 1 & 0 & 0 & $\mathbf{3}$ \\
\hline Total general & $\mathbf{7}$ & $\mathbf{2}$ & $\mathbf{1}$ & $\mathbf{1}$ & $\mathbf{1 1}$ \\
\hline
\end{tabular}

Tabla 2. Distribución de los grupos tipológicos por materia prima.

\begin{tabular}{|c|c|c|c|c|c|c|c|c|c|c|}
\hline \multirow[t]{2}{*}{ Materia prima } & \multicolumn{2}{|c|}{ Núcleos } & \multicolumn{2}{|c|}{ Desechos de talla } & \multicolumn{2}{|c|}{$\begin{array}{c}\text { Artefactos } \\
\text { con rastros } \\
\text { complementarios }\end{array}$} & \multicolumn{2}{|c|}{ Instrumentos } & \multicolumn{2}{|c|}{$\begin{array}{l}\text { Total por materia } \\
\text { prima }\end{array}$} \\
\hline & $\mathbf{N}$ & $\%$ & $\mathbf{N}$ & $\%$ & $\mathbf{N}$ & $\%$ & $\mathbf{N}$ & $\%$ & $\mathbf{N}$ & $\%$ \\
\hline Andesita G & 15 & 2,08 & 328 & 45,49 & 5 & 0,69 & 7 & 0,97 & 355 & 49,23 \\
\hline Andesita $\mathrm{P}$ & 2 & 0,27 & 37 & 5,13 & 1 & 0,13 & 1 & 0,13 & 41 & 5,68 \\
\hline Andesita B & 9 & 1,24 & 225 & 31,20 & 2 & 0,27 & 13 & 1,80 & 249 & 34,53 \\
\hline Cuarcita & o & o & 4 & 0,55 & o & o & 1 & 0,13 & 5 & 0,69 \\
\hline Cuarzo & 4 & 0,55 & 57 & 7,90 & o & o & 4 & 0,55 & 65 & 9,01 \\
\hline Metamorfitas & o & o & 3 & 0,41 & o & o & o & o & 3 & 0,41 \\
\hline Sílice & 0 & o & 1 & 0,13 & o & o & 1 & 0,13 & 2 & 0,27 \\
\hline Obsidiana & $\mathrm{o}$ & o & 1 & 0,13 & o & o & o & o & 1 & 0,13 \\
\hline $\begin{array}{l}\text { Total por clase } \\
\text { tipológica }\end{array}$ & 30 & 4,14 & 656 & 90,94 & 8 & 1,09 & 27 & 3,71 & 721 & 100 \\
\hline
\end{tabular}

Tabla 3. Distribución de artefactos líticos según clase tipológica y materias primas.
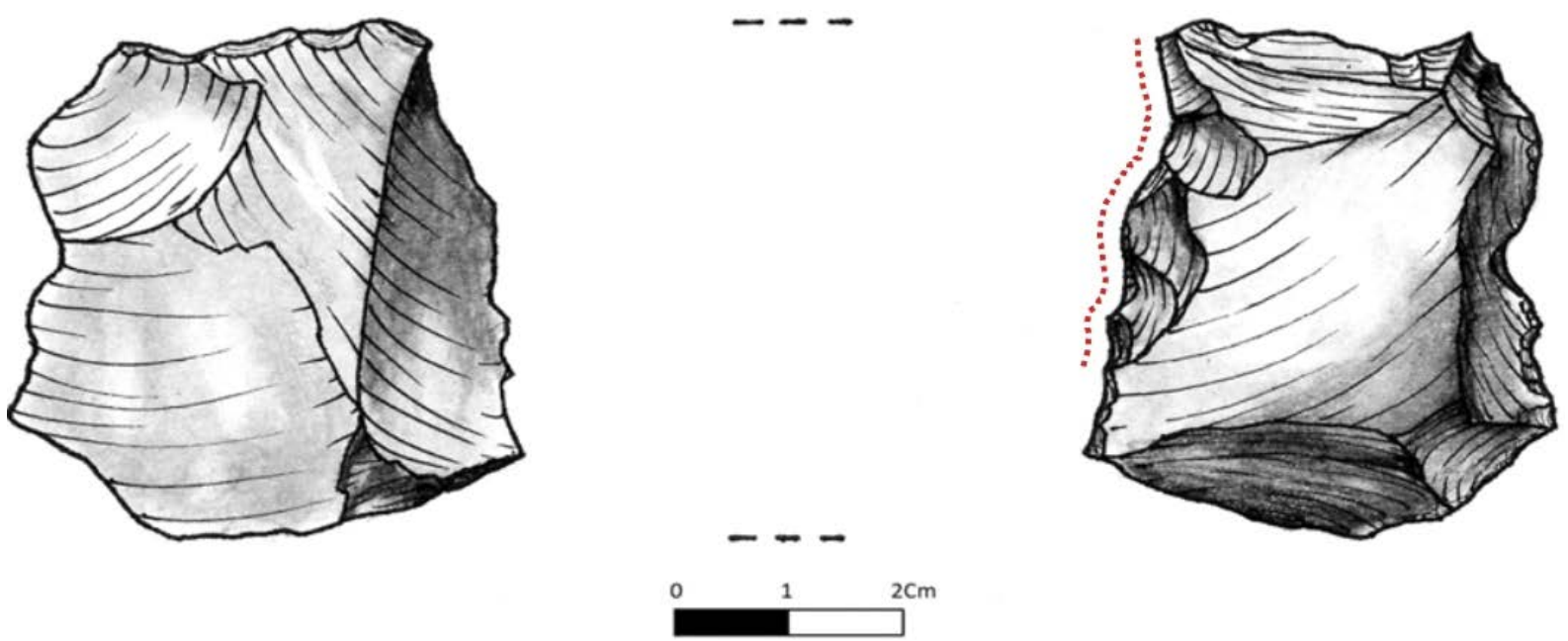

Figura 3. Artefacto compuesto, formatizado sobre lasca angular (La línea de puntos marca el filo activo).

\section{Núcleos}

Los núcleos $(\mathrm{n}=30)$ corresponden al 4,14\% del total de la muestra de artefactos líticos. Corresponden a materias primas locales con un predominio de andesita $\mathrm{G}$ con el 50\%, seguido por la B con el $30 \%$. 


\begin{tabular}{|l|c|c|c|c|c|}
\hline \multirow{2}{*}{ Designación morfológica } & \multicolumn{5}{|c|}{ Materias primas } \\
\cline { 2 - 6 } & Andesita B & Andesita G & Andesita P & Cuarzo & Total \\
\hline Poliédrico & 4 & 3 & 0 & 2 & 9 \\
Con lascados aislados & 1 & 7 & 0 & 2 & 10 \\
Discoidal & 1 & 0 & 0 & 0 & 1 \\
Bifacial & 0 & 1 & 0 & 0 & 1 \\
Piramidal irregular & 0 & 1 & 0 & 0 & 1 \\
Fragmento no diferenciado & 3 & 3 & 2 & 0 & 8 \\
\hline Total & $\mathbf{9}$ & $\mathbf{1 5}$ & $\mathbf{2}$ & $\mathbf{4}$ & 30 \\
\hline
\end{tabular}

Tabla 4. Distribución de la designación morfológica de los núcleos en relación a la materia prima.

En cuanto a la designación morfológica, su distribución se expresa en la Tabla 4. En la misma se observa el amplio espectro que manifiesta marcando una interesante variabilidad. Predominan los núcleos con lascados aislados y el $70 \%$ de estos corresponden a andesita $\mathrm{G}$, lo que indicaría que, si bien esta variedad es abundante en la zona, esta materia prima es seleccionada a partir del testeo de sus nódulos. A estos le siguen los núcleos poliédricos, representados en proporciones similares en las andesitas B y G. No podemos dejar de lado la presencia de núcleos piramidales, discoidales irregulares y bifaciales dentro de la muestra que, aunque en muy bajas proporciones, marcarían cierto grado de estandarización de formas base.

Aproximadamente el 70\% de los núcleos responden a las dimensiones de tamaños grande y muy grande lo cual indicaría que aún pueden seguir siendo utilizados. Al tomar las dimensiones tamaño y módulo longitud-anchura de las últimas extracciones se desprende que las últimas lascas extraídas corresponden a tamaños mediano pequeño, mediando grande y grande con módulos que varían entre mediano normal y corto muy ancho.

\section{Desechos de talla}

En total se analizaron 656 desechos de talla que corresponden al 91\% de la muestra total. Como se expuso anteriormente, el $98 \%$ de los mismos corresponden a materias primas locales y el $2 \%$ restante está representado por materias primas no locales como la cuarcita y la obsidiana. En total los desechos de andesitas suman 590 (90\%), con predominio de la $\mathrm{G}$ en un $50 \%$, le sigue la $\mathrm{B}$ con un $35 \%$ y en menor proporción la $\mathrm{P}$ en un 6\%. En este caso el cuarzo tiene una baja representatividad en la muestra (8\%). Aquí aparecen, aunque escasamente representadas $(n=3)$, lascas en metamorfitas $(0,4 \%)$. En lo que refiere a materias primas no locales, entre las mismas se encuentran la cuarcita, la obsidiana y la sílice, todas presentes en muy bajas proporciones.

Del estado de fragmentación se destacan lascas fracturadas con y sin talón (70\%), le siguen desechos enteros (27\%) y en menor porcentaje lascas indiferenciadas (3\%). La variable origen de las extracciones resulta importante al momento de definir las etapas de la secuencia de producción. Para este análisis sólo se consideraron lacas enteras y fracturadas con talón $(n=530)$. Predominan lascas internas con un $82 \%(n=436)$ sobre el total de la muestra. Un alto porcentaje de las mismas corresponde con andesita variedad G. Del total de lascas, 399 son angulares (90\%). Esto evidenciaría tareas de extracción primaria (reducción primaria o talla) y de formatización (reducción secundaria: retalla, retoque o microretoque). Las lascas externas se encuentran presentes con un $15 \%$ y predominan las andesitas G (48\%), le siguen las B (35\%) y en menor proporción las $\mathrm{P}(8 \%)$ y el cuarzo (7\%). Sabemos que estos desechos son el resultado 
de tareas extracción primaria. En este caso el predominio de la andesita G coincide con la mayor presencia de núcleos de esta materia prima en el sitio.

Las lascas de adelgazamiento bifacial, asociadas a recursos locales (andesitas G y B), presentan una muy baja frecuencia en el registro lítico de la transecta, lo que se traduciría en un escaso énfasis en la realización de estas tareas. Esto se refleja, además, entre los instrumentos.

Las tareas de reactivación de núcleos se encuentran presentes aunque en una baja frecuencia (2\%) lo que es lógico teniendo en cuenta la cercanía a las fuentes. Lo llamativo es que se encuentra asociada a un recurso local. En este caso el predominio de andesita $\mathrm{G}$ coincide con la mayor variabilidad de núcleos que encontramos de esta materia prima en el sitio.

Para las variables tamaño y módulo longitud-anchura sólo se consideraron lascas enteras. El 90\% de la muestra corresponde a tamaños medianos pequeños, medianos grandes y grandes. La presencia de tamaños pequeños y grandísimos no puede ser dejada de lado ya que dan cuenta de actividades tanto de reducción primaria como secundaria en el sitio. Los resultados del análisis de lascas enteras a través del módulo longitud-anchura corresponden a los tamaños mediano normal, seguido por los cortos anchos y en tercer lugar los medianos alargados. Entre los talones, $71 \%$ son preparados predominando los talones lisos sobre los demás. El 29\% restante representa talones corticales.

\section{Instrumentos}

Los instrumentos suman 27 y conforman el 3,7\% del total de materiales correspondientes a la transecta $(n=721)$. En relación a la distribución de recursos líticos, el $92 \%$ de los instrumentos fueron manufacturados sobre recursos locales, particularmente andesitas. Dentro de éstas se da un claro predominio de la B (48\%) sobre la G (26\%) y se halla presente el cuarzo en menor proporción (14\%). Como materia prima no local tenemos cuarcita y sílice, que aparecen en un solo ejemplar cada uno.

El estado de fragmentación muestra solo 10 instrumentos parcialmente fracturados y que aun presentan posibilidades de uso mediante reactivaciones, con lo cual se deja de lado la posibilidad de descarte. El 66\% corresponde a tamaños grandes. Asimismo están presentes en proporciones menores, pero similares entre sí, las categorías medianas pequeñas, muy grandes y medianas grandes. Los resultados en relación al módulo longitud-anchura indican que el 55\% de los instrumentos responden a la categoría mediano normal. En segundo lugar se encontrarían los módulos medianos alargados con el $26 \%$ y las restantes categorías se encuentran en menores proporciones.

La Tabla 5 presenta la distribución de las formas base sobre las cuales fueron confeccionados los instrumentos. Se observa que cerca del $40 \%$ de los instrumentos poseen como formas base lascas internas, predominando las lascas angulares (37\%) a las que le siguen las formas base no diferenciadas ${ }^{1}(29 \%)$ y en tercer lugar las lascas externas (26\%). La frecuencia de aparición de lascas angulares como formas base de los instrumentos coincide con la frecuencia de aparición entre los desechos, ya que además este tipo de lasca es el que se encuentra mayormente representado.

A continuación se presentan los instrumentos en relación con la variable grupos tipológicos según la materia prima (Tabla 6). Los grupos tipológicos predominantes son muescas de lascado simple, cuchillos de filo natural y filo retocado y denticulados en su mayoría confeccionados sobre andesita B. A estos le siguen en cantidad muescas retocadas, artefactos de formatización sumaria, raspadores y raederas, todos 


\begin{tabular}{|c|c|c|c|c|c|c|}
\hline $\begin{array}{c}\text { Lasca } \\
\text { Primaria }\end{array}$ & Lasca Angular & Lasca de arista & $\begin{array}{c}\text { Lasca Con Dorso } \\
\text { Natural }\end{array}$ & Nódulo & No Diferenciado & Total \\
\hline 5 & 10 & 1 & 2 & 1 & 8 & $\mathbf{2 7}$ \\
\hline $18,51 \%$ & $37,03 \%$ & $3,70 \%$ & $7,40 \%$ & $3,70 \%$ & $29,62 \%$ & $100 \%$ \\
\hline
\end{tabular}

Tabla 5. Distribución de las formas base de los instrumentos.

\begin{tabular}{|c|c|c|c|c|c|c|c|}
\hline \multirow{2}{*}{ Grupo tipológico } & \multicolumn{7}{|c|}{ Materias primas } \\
\hline & Andesita G & Andesita B & Andesita P & Cuarzo & Cuarcita & Sílice & Total general \\
\hline $\begin{array}{l}\text { Artefacto con } \\
\text { formatización sumaria }\end{array}$ & 1 & 0 & 0 & 1 & 0 & 0 & 2 \\
\hline Artefacto burilante & o & o & o & o & o & 1 & 1 \\
\hline Cuchillo de filo natural & 1 & 2 & o & o & o & o & 3 \\
\hline Cuchillo filo retocado & 1 & 3 & o & o & o & o & 4 \\
\hline Denticulado & o & 1 & o & 1 & 1 & o & 3 \\
\hline Muesca de lascado simple & 1 & 3 & o & $\mathrm{o}$ & o & o & 4 \\
\hline Muesca retocada & 1 & 1 & o & o & o & o & 2 \\
\hline Percutor & o & o & o & 1 & o & o & 1 \\
\hline Raedera & 1 & 1 & o & o & o & o & 2 \\
\hline Raspador & 1 & 2 & o & o & o & o & 3 \\
\hline $\begin{array}{l}\text { Filo bifacial de arista } \\
\text { sinuosa }\end{array}$ & o & 1 & o & o & o & o & 1 \\
\hline $\begin{array}{l}\text { Fragmento de artefacto no } \\
\text { diferenciado }\end{array}$ & o & o & o & 1 & o & o & 1 \\
\hline Total general & 7 & 13 & 1 & 4 & 1 & 1 & 27 \\
\hline
\end{tabular}

Tabla 6. Distribución de los grupos tipológicos por materia prima.

manufacturados sobre andesitas B y G. Los grupos tipológicos restantes aparecen solo en un ejemplar cada uno, un artefacto burilante y un filo bifacial de arista sinuosa.

Del total de los instrumentos mencionados, nueve pertenecen a la categoría de artefactos compuestos y fueron confeccionados sobre andesita. El filo bifacial de arista sinuosa presenta una muesca de lascado simple como dorso (Figura 4), la raedera, el cuchillo de filo natural y un artefacto con formatización sumaria también presentan cada uno una muesca de lascado simple, que considerando su posición también podrían haber funcionado como dorso en cada caso. Por otra parte tenemos una punta burilante que combina con una raedera y un raspador el cual tiene como grupo complementario una muesca retocada. El cuchillo de filo retocado posee una punta entre muescas. Una raedera cuenta con un artefacto de formatización sumaria y por último un artefacto de formatización sumaria combina con una muesca de lascado simple.

Es importante destacar que se observa cierta variabilidad entre los filos que se combinan en los artefactos compuestos. Dentro de los instrumentos formatizados compuestos notamos el alto porcentaje de muescas de lascado simple o retocadas como uno de los grupos tipológicos combinados. Al respecto pensamos que estas funcionarían a modo de dorso de los artefactos en cuestión. A excepción del filo bifacial, todos los instrumentos son unifaciales. Con respecto a la serie técnica implementada en la formatización de los instrumentos puede decirse que hay un marcado énfasis en el retoque marginal, ya que el $90 \%$ de las piezas presentan esta serie técnica. Le siguen el microrretoque marginal y la talla marginal. 


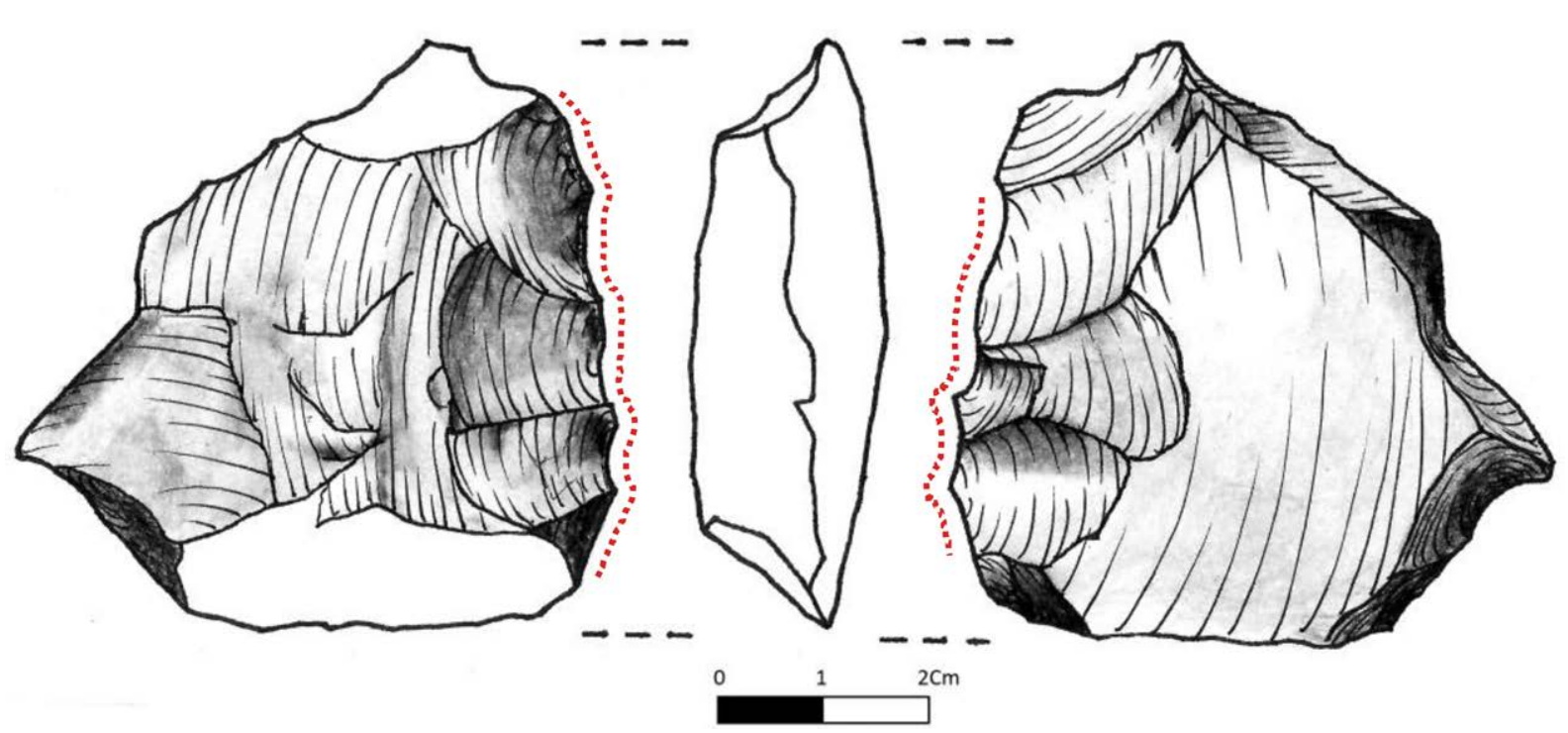

Figura 4. Instrumento compuesto. Filo bifacial de arista sinuosa y muesca de lascado simple como dorso (La línea de puntos marca el filo activo).

Filos naturales con rastros complementarios (FNRC)

El total de FNRC recuperados en la recolección superficial es de nueve. Seis de estas piezas fueron trabajadas sobre andesita G, dos en basandesita y solo un ejemplar en la variedad $\mathrm{P}$. Al considerar el estado de fragmentación, se presentan cuatro instrumentos enteros y cinco fracturados. Predominan lascas angulares como formas base en un $70 \%$, mientras que el $30 \%$ restante son lascas primarias. El tamaño de estos artefactos varía entre medianos pequeños y grandes con modulo mediano normal.

\section{Discusión y conclusiones}

\section{Materias primas y disponibilidad}

A partir del análisis de aspectos relacionados con la obtención y uso de materias primas fue posible observar un uso diferencial entre las rocas locales y las no locales. Vale recordar que fueron considerados locales aquellos recursos disponibles a no más de $20 \mathrm{~km}$ de distancia desde el sitio. Este es el caso de las tres variedades de andesitas (B, G y P), el cuarzo y las metamorfitas. En el espacio de emplazamiento y sus proximidades no se encuentran afloramientos rocosos que se correspondan con las materias primas utilizadas. Esto permite sostener que el río Amaicha es la principal fuente de aprovisionamiento de recursos locales en general, accesible a una distancia que no supera los $500 \mathrm{~m}$. Abunda fundamentalmente la variedad de andesita G, seguida por las variedades B, P, cuarzo y metamorfitas en forma de nódulos rodados, distribuidos a lo largo del cauce. Entre los recursos no locales encontramos a la cuarcita, cuya fuente se encontraría en un sector del basamento de Sierras del Aconquija, a una distancia de alrededor de $20 \mathrm{~km}$ desde el sitio. Por este motivo fue considerada como un recurso no local en este trabajo, pese a ser el más próximo dentro de este grupo de materias primas. El caso de la obsidiana es diferente ya que su fuente, probablemente Ona, está ubicada a más de $150 \mathrm{~km}$. Por último tenemos a la sílice, de la cual se desconoce su fuente y, teniendo en cuenta la forma en que se presenta en los conjuntos, fue considerada como no local en este trabajo.

En cuanto a la calidad de las materias primas, en base a las características físicas de las rocas se consideró que entre las locales la basandesita sería uno de los recursos que 
mejores cualidades ofrecen para la talla, al igual que la obsidiana y el resto de recursos no locales, presentes en menor proporción en el sitio, y cuya obtención implicaría costos de aprovisionamiento marcadamente diferentes. Al respecto, en El Remate observamos que en los conjuntos líticos analizados, tanto de excavación como de recolección superficial, el 99\% corresponde a materias primas locales, especialmente andesitas en sus variedades $\mathrm{G}$ y $\mathrm{B}$ y cuarzo. El $1 \%$ restante corresponde a las no locales. Esto nos permite sostener un aprovechamiento diferencial de los recursos directamente relacionado con la disponibilidad y accesibilidad de los mismos. Si bien parecería funcionar así para las materias primas locales y no locales, se ha notado también entre las andesitas cierto uso diferencial. Si tomamos los núcleos como un ejemplo, el 51\% de estos corresponde a la variedad G, el 32\% a basandesita, siendo inferior al 5\% la presencia de la variedad P. Este uso diferencial se hace extensivo a los restantes recursos locales donde notamos que aproximadamente el $10 \%$ corresponde a núcleos de cuarzo mientras que no se han recuperado núcleos de metamorfitas, más allá de encontrarse desechos de talla en esta materia prima. De aquí se desprende que, dada la variabilidad de recursos disponibles, la explotación estuvo centrada en las andesitas G y B y, en tercer lugar, el cuarzo. Esto se relacionaría con la importancia que tuvo la selección de materias primas con mejores cualidades, a pesar de que los recursos estuvieron disponibles en similares proporciones en el río Amaicha.

En relación con los tamaños de los núcleos notamos que el $88 \%$ corresponde a las categorías grande, muy grande y grandísimo. Como ya se mencionó, en las cercanías del sitio hay una amplia disponibilidad de materias primas, la cual coincidiría con el predomino de núcleos de tamaños considerables que se encuentran lejos de estar agotados. También debemos mencionar la presencia de núcleos de tamaños mediano pequeño, en menor proporción, que indicarían cierto grado de maximización en el uso de la materia prima, asociado en este caso a la basandesita, seguido por andesitas G y P y la cuarcita.

De la muestra total se destaca el predominio de núcleos con lascados aislados. Esta designación morfológica se encuentra directamente relacionada al testeo de la materia prima, y dada la cercanía a la fuente, estaría indicando el ingreso de los núcleos al sitio como nódulos ya testeados. Esto podría ser pensado como una forma de traslado del material de buena calidad desde la fuente, a modo de 'acopio'.

Entre los tipos de lascas representados en la muestra de desechos, registramos bajas proporciones de lascas de reactivación de núcleos, algo que es lógico dada la proximidad de la fuente. No obstante, resulta llamativo que este tipo de lascas se encuentre relacionado a la andesita $\mathrm{G}$, recurso local. Con respecto a las formas base de los instrumentos, simples y compuestos, es importante destacar que el 76\% de las mismas corresponde a las andesitas B y G, seguido por el cuarzo con el 15\% y la cuarcita $5 \%$. Si bien existe cierta variabilidad entre los tamaños de los instrumentos, el predominio de tamaños grandes en un 70\% se relaciona con las dimensiones importantes de los núcleos y los tamaños de las potenciales formas base. Estos datos nos indican que las andesitas B y G, y en tercer lugar el cuarzo, serían los principales recursos a la hora de la elección de la materia prima para la formatización de los instrumentos. Las menores dimensiones y la baja proporción de los artefactos en general de materias primas no locales indicarían la maximización en el uso de estos recursos debido a que los costos de obtención de los mismos son mucho mayores.

En general es poca la inversión de trabajo registrada entre los conjuntos líticos. Muchos instrumentos, aún en los casos en que se encuentran fracturados, presentan posibilidades de ser reactivados. Sin embargo, no se identificaron actividades de mantenimiento ni reciclaje entre los mismos, lo que quizás se deba a la amplia disponibilidad de los recursos en las cercanías del área. Más allá de la disponibilidad de las materias primas, 
entre los conjuntos artefactuales se vio reflejado el uso diferencial de las mismas, donde notamos el predominio de andesitas G, B y cuarzo, lo cual estaría indicando cierto grado de selección, por parte de los grupos humanos, de recursos que presentan mejores cualidades para la talla. La menor proporción de andesitas P en el sitio quizá se debió a una baja disponibilidad en la fuente.

En relación con las materias primas no locales encontramos tres tipos diferentes en la muestra total de artefactos líticos: cuarcita, sílice y obsidiana. Como dijimos, el porcentaje de estas es poco representativo, ya que suman el 1\% del total. En las excavaciones de E49 fueron recuperados artefactos de cuarcita y obsidiana mientras que en la recolección superficial encontramos además sílice.

Es importante destacar que la cuarcita se encuentra representada en casi todas las clases tipológicas. La fuente se encontraría a una distancia alrededor de $20 \mathrm{~km}$, por lo tanto es posible pensar que los grupos humanos se habrían trasladado a esta zona para acceder a nódulos que luego serían llevados al sitio. Es por esto que dentro de este grupo de materias primas no locales, es el recurso que predomina.

Como ya se manifestó, es desconocida la procedencia de la sílice gris oscuro. La presencia de solo un desecho de talla y las características del artefacto formatizado invitan a pensar que esta materia prima ingresó al sitio ya formatizada o en un estado avanzado de formatización.

En relación con la obsidiana sólo tres artefactos han sido recuperados notándose la ausencia de núcleos e instrumentos entre los mismos. Esta materia prima ha sido registrada en otros sitios contemporáneos de la zona en contextos similares (Caria, Escola, Augier y Glascock, 2009; Chiappe Sánchez, 2007; Germano et al., 2007; Somonte, 2007). Lo importante es saber cómo llega esta materia prima al sitio sabiendo que la fuente de Ona se encuentra a más de $150 \mathrm{~km}$. La obsidiana fue registrada en muchos de los sitios del noroeste argentino asociada a diferentes contextos, lo que hace difícil establecer si esta materia prima fue considerada como exótica o de uso cotidiano en cada caso. Al respecto, Scattolin y Lazzari (1997) se refieren a la creación y re-creación de redes de circulación de esta materia prima, por parte de los grupos, que pudieron haber estado o no relacionadas con otros materiales. El punto importante es que en estas acciones se encuentran involucrados diferentes factores sociales que esconderían formas diversas de interacciones sociales importantes para tener en cuenta al momento evaluar y discutir aspectos movilidad e intercambio (Scattolin y Lazzari, 1997). En El Remate, dada la escasa presencia de obsidiana recuperada hasta el momento, se torna difícil establecer el uso que pudo haber tenido esta materia prima. En el sitio Bajo Los Cardones fueron recuperadas puntas de proyectil con evidencia de reactivación, lo que mostraría la maximización en el uso de este recurso no local (Somonte, 2002).

A modo de síntesis podemos decir que los resultados obtenidos a partir de este análisis, presentan un marcado énfasis en el uso de materias primas locales dada su disponibilidad accesibilidad a las fuentes cercanas.

\section{Secuencia de producción lítica}

Los resultados del análisis de los conjuntos líticos de E49 y de superficie evidencian la realización de todas las etapas de la secuencia de producción (obtención, manufactura, uso y descarte), encontrando algunas particularidades en el énfasis con el que se desarrollaron en cada caso.

El número total de núcleos recuperados en $\mathrm{E} 49$ es de 13, mientras que en la recolección superficial se recuperaron 30 . Es notorio en ambos casos el predominio de los tamaños 
grandes, muy grande y grandísimo (cerca del 90\%) siendo menor la proporción de tamaños medianos y pequeños. En cuanto a las designaciones morfológicas encontramos que en E49 la muestra está compuesta de núcleos poliédricos y con lascados aislados. Los núcleos poliédricos se caracterizan por presentar extracciones en diferentes direcciones sin una búsqueda de formas base estandarizadas. Con respecto a la designación con lascados aislados, sabemos que estos núcleos podrían relacionarse con el testeo de materia prima. En las afueras de la estructura encontramos una mayor variabilidad de núcleos. Si bien predominan núcleos con lascados aislados y poliédricos, la presencia de núcleos bifaciales, discoidales y piramidales irregulares indicaría que la búsqueda estandarizada de formas base estuvo presente, aunque en menores proporciones. Los núcleos en general, tanto en la muestra de $\mathrm{E} 49$ como de superficie, no presentan evidencias de agotamiento, manifiestan pruebas de testeo y extracción de diversas formas base y su explotación no se encuentra relacionada a ninguna intención clara de maximización de las materias primas.

Considerar el análisis de los desechos de talla es importante para poder inferir actividades tecnológicas desarrolladas en el sitio. Recordemos que para la evaluación de estos datos, fueron consideradas lascas enteras y fracturadas con talón. Tanto en el recinto como en la recolección superficial pudimos apreciar el predominio de lascas internas (83\% en E49 y 82\% en recolección superficial) y en segundo lugar las externas, correspondientes a las primeras etapas de extracción, con un porcentaje que no debe ser descartado (16\% en E49 y 15\% en recolección superficial). Estos datos son útiles y complementan las evidencias de los núcleos, ya que su presencia nos advierte sobre la realización de actividades de reducción de núcleos y extracción de formas base.

Entre las lascas internas notamos que tanto en el recinto como en las afueras predominan los desechos angulares, seguidos por lascas de arista y en mínimas proporciones las lascas planas. La presencia de lascas de adelgazamiento bifacial es casi nula en el sitio, así como los instrumentos bifaciales en sentido amplio. El 90\% de los instrumentos, de las dos muestras, presenta formatización sólo en una de sus caras.

En relación con el estado de fragmentación, entre los desechos notamos que en el recinto cerca del $70 \%$ de la muestra corresponde a lascas fracturadas, mientras que el 30\% restante son lascas enteras e indiferenciadas. Esto nos sugiere que se dieron actividades de reducción primaria y secundaria con predominio de tareas de manufactura y/o formatización sobre las de reducción primaria. Estos datos son importantes si tenemos en cuenta que el recinto ha sido definido como patio central (Aschero y Ribotta, 2007), lugar en el que sería esperable este tipo de actividades, relacionadas a la formatización de los instrumentos. Los resultados obtenidos a partir del análisis de los materiales recolectados en la transecta (68\% lascas fracturadas, $28 \%$ lascas enteras y $3 \%$ indiferenciadas) indican la presencia tanto de manufactura y formatización como así también de reducción de núcleos. Sin embargo, el predominio de desechos fracturados conduce a pensar que se habrían dado con mayor énfasis tareas de reducción secundaria. Aquí es importante tener en cuenta que los materiales analizados provienen de superficie y, por lo tanto, estuvieron expuestos a diferentes procesos que podrían provocar desechos fracturados.

$\mathrm{Al}$ considerar las variables tamaño y módulo longitud-anchura, encontramos que dentro del recinto los tamaños pequeños representan el 18\%, lo cual indicaría la presencia de formatización de las piezas. En el caso de recolección superficial este tamaño representa casi un $6 \%$ con lo cual podríamos decir que este tipo de actividad se realizó con mayor frecuencia en el patio. Es evidente el predominio de los tamaños mediano pequeño, mediano grande y grande entre los desechos, tanto en el recinto como en las afueras, siendo los de tamaño grande los más representativos, con módulos mediano normal y corto ancho en su mayoría. Si tomamos esta variable y la comparamos con los tamaños 
de los artefactos vemos que hay semejanzas, ya que predominan los de tamaño grande, con lo cual podemos decir que entre los desechos tendríamos potenciales formas base producto de la reducción de núcleos. No se registró mantenimiento en los artefactos, dado que no se registraron desechos muy pequeños ni lascas de reactivación de artefactos que indiquen este tipo de actividad. Los datos obtenidos a partir de los desechos de E49 indican la presencia de tareas de reducción primaria y secundaria. Pero, si tenemos en cuenta que el recinto funcionó como patio, es lógico encontrar evidencia de núcleos, formas base, desechos de talla e instrumentos, independientemente del énfasis con el que se hayan desarrollado cada una de las actividades inherentes a la secuencia de producción.

La información obtenida en relación con la forma de los talones de los desechos del interior del recinto, indica un predominio de los talones preparados (83\%) sobre los corticales (17\%). La baja proporción de estos últimos estaría indicando la escasa realización de actividades de reducción primaria. Esto es compatible con la mayor presencia de lascas internas en el recinto. Similar es el caso de la recolección de superficie, donde tenemos un predominio de talones preparados con un $70 \%$, destacándose la presencia de talones lisos sobre los demás, mientras que el 30\% restante representaría talones corticales. Aquí encontramos un mayor énfasis en las actividades de reducción primaria si lo comparamos con los porcentajes del recinto.

Es importante mencionar la escasa representatividad de lascas de reactivación de núcleos, algo esperable ya que, como fuera mencionado previamente, la explotación y el agotamiento de los núcleos se encuentra directamente relacionado con la disponibilidad de recursos líticos en la zona.

Hasta aquí podemos decir que en E49 los desechos de talla manifiestan una mayor diversidad de materias primas en relación con los núcleos y los artefactos formatizados, lo que probablemente marcaría el traslado de instrumentos desde el recinto hacia otras localizaciones o sectores dentro del mismo sitio. La recolección superficial presenta cierta diversidad entre las materias primas de los desechos, acompañada por una mayor variabilidad entre núcleos e instrumentos. En este caso la búsqueda de formas base estandarizadas se encuentra representada en una baja proporción, la cual, además de la presencia de lascas de arista entre desechos, está reafirmada por los soportes de los instrumentos y los tipos de núcleos presentes en la superficie. En relación con los instrumentos, en el recinto encontramos un total de 11 mientras que en superficie fueron recolectados 27. Los grupos tipológicos predominantes en el recinto son denticulados y artefactos de formatización sumaria. Aquí encontramos solo dos instrumentos compuestos dobles y son el caso de dos denticulados combinando formatización sumaria en sus filos opuestos. También es destacable la presencia de un cuchillo, una muesca retocada y la punta de proyectil.

En relación con los instrumentos de superficie, notamos una mayor variabilidad de grupos tipológicos donde predominan cuchillos (de filo natural y filo retocado), denticulados, raederas, raspadores, muescas y artefactos de formatización sumaria. Solo un ejemplar corresponde a una punta burilante y un filo bifacial de arista sinuosa. Del total de instrumentos mencionados, nueve son compuestos donde combinan con muescas de lascado simple en su mayoría. En términos generales los artefactos compuestos combinan diversos filos (raederas, cuchillos, raspadores, con formatización sumaria) con muescas de lascado simple o retocada. Esto, sumado a la posición de ambos filos en la pieza, invita a considerar la presencia de estas muescas con un fin prensil.

Si consideramos estos datos y la serie técnica es posible decir que, en general, los instrumentos presentan un tipo de manufactura simple, unifacial, donde predomina el retoque marginal. Este es el caso de cuchillos, denticulados, raspadores, raederas, 
muescas de lascado simple, muescas retocadas y artefactos de formatización sumaria. Pero no podemos dejar de mencionar instrumentos como el filo bifacial de arista sinuosa y la punta de proyectil, los cuales estarían manifestando una mayor inversión de trabajo.

El bajo porcentaje de artefactos líticos sobre recursos no locales, que además presentan tamaños reducidos y ausencia de corteza, indicaría que los mismos ingresarían al sitio en las últimas etapas de la secuencia de producción.

Entre los instrumentos recuperados en superficie encontramos cierta variabilidad al momento de la elección de formas base. Notamos el predominio de lascas angulares seguido por lascas externas (primarias, secundarias y con dorso natural), una lasca de arista, un fragmento de núcleo y formas base no diferenciadas. Si bien es notoria la ausencia de formas base estandarizadas, la presencia de los núcleos prismático irregular, discoidal y bifacial y un cuchillo retocado que combina una formatización sumaria, cuya forma base es una lasca de arista, nos indicarían la búsqueda de cierta estandarización. En relación a este cuchillo retocado, es importante destacar que la formatización sumaria en su filo opuesto presenta evidencias de haber sido formatizado en un momento posterior. Esto es posible inferirlo debido a la diferenciación de tonalidades que existe entre los lascados. Por otra parte, en E49 notamos que las actividades de regularización, formatización y mantenimiento de filos están pobremente representadas entre los desechos ya que mínima la presencia de tamaños pequeños, esto es coherente ya que no se registró mantenimiento entre los filos de los instrumentos a excepción de la punta de proyectil la cual, además, presenta lascados que cubren completamente sus caras.

La fragmentación entre los instrumentos se encuentra presente en ambas muestras. Dentro del recinto, el $50 \%$ de los instrumentos presenta fracturas y en el caso de superficie un $35 \%$, es importante dejar en claro que las fracturas son mínimas entre los mismos. A esto se suma que un alto porcentaje de instrumentos fracturados presenta tamaños grandes, lo que indicaría que aún presentan posibilidades de reactivación.

A partir del análisis de los conjuntos líticos de El Remate podemos decir que tanto en E49 como en la muestra de superficie se encuentran presentes todas las actividades relacionadas con las distintas etapas de la secuencia de producción. Si tenemos en cuenta que el recinto funcionó como patio, es lógico encontrar núcleos, formas base, desechos de talla y artefactos formatizados, lo mismo puede decirse de los conjuntos de recolección superficial, aunque aquí encontramos mayor variabilidad en cuanto al uso de materias primas y en las formas base de los instrumentos. Teniendo en cuenta esta mayor variabilidad entre los conjuntos líticos de superficie, es importante considerar la historia ocupacional del área e intentar explicar de qué manera poblaciones posteriores utilizaros estos espacios. Al respecto, Somonte (2007) plantea que la mayor variabilidad ocupacional en Amaicha del Valle se encuentra en sitios a cielo abierto y resulta de diferentes momentos ocupacionales. Esto se infiere, junto con otros elementos, a partir de la evidencia de reclamación artefactual registrada a partir de las diferentes tonalidades de las pátinas (Somonte, 2007). Esta reclamación queda evidenciada con la presencia del cuchillo bifacial con formatización sumaria. Las características de E49, tales como la clausura de uno de los accesos al recinto y los dos momentos ocupacionales, presentan ciertas similitudes con lo hallado en el sitio Bajo los Cardones (Somonte, 2005). Estos datos, sumados a la presencia de artefactos descartados en condiciones de seguir siendo utilizados, dan cuenta de una recurrencia ocupacional y sugieren la posibilidad de situaciones de retorno a los sitios.

En base a la distribución de los recursos líticos disponibles en Amaicha, podemos decir que la secuencia de producción debió iniciarse en el río Amaicha. Ahí se habrían llevado a cabo actividades de selección y recolección de materias primas pero además, 
la presencia de artefactos con patinas diferenciadas sugieren que en el mismo sitio habría iniciado la secuencia de producción en momentos diferentes. En este caso las actividades llevadas a cabo en estos diferentes lugares de aprovisionamiento habrían sido diferentes. En E49 se realizaron actividades de reducción primaria y extracción de formas base y, en menor grado, formatización y regularización de instrumentos y descarte. Una situación similar en relación a esta variabilidad fue registrada en sitios cercanos en Amaicha, como Bajo Los Cardones y Campo Blanco (Germano et al., 2007; Somonte, 2005), y en localidades vecinas como Quebrada de Los Corrales (Oliszewski 2011; Oliszewski, Caria y Martínez, 2013; Oliszewski et al., 2008) y en el valle de Santa María (Carbonelli, 2009, 2011; Gaál y Carbonelli, 2012).

\section{Agradecimientos}

Este trabajo se realizó con fondos del proyecto CIUNT G-406. Agradezco a Marco Giusta por la revisión del manuscrito. A Alfredo Calisaya por los dibujos de los instrumentos. A Carolina Somonte y Carlos Baied, gracias por todo. 


\section{Referencias citadas}

» Aschero C. A. (1975). Ensayo para una clasificación morfológica de artefactos líticos aplicada a estudios tipológicos comparativos. Informe al CONICET. Manuscrito inédito.

" Aschero C. A. (1983). Ensayo para una clasificación morfológica de artefactos líticos. Apéndices A y B. Facultad de Filosofía y Letras. UBA. Manuscrito inédito.

» Aschero C. A. (1988). De punta a punta: producción mantenimiento y diseño en puntas de proyectil precerámicas de la puna argentina. Trabajo presentado en el IX Congreso Nacional de Arqueología Argentina, Buenos Aires, Argentina.

»Aschero, C. A. y Hocsman, S. (2004). Revisando cuestiones tipológicas en torno a la clasificación de artefactos bifaciales. En M. Ramos, A. Acosta y D. Loponte (Eds.), Temas de Arqueología. Análisis lítico (pp. 7-25). Luján: Universidad Nacional de Luján.

» Aschero, C. A., Moya, L., Sotelos, C. y Martínez, J. (1995). Producción lítica en los límites del bosque cordillerano: el sitio Campo Río Roble 1 (Santa Cruz, Argentina). Relaciones de la Sociedad Argentina de Antropología, XX, 205-238.

" Aschero, C. A. y Ribotta, E. (2007). Usos del espacio, tiempo y funebria en El Remate (Los Zazos, Amaicha del Valle, Tucumán). En P. Arenas, B. Manase y E. Noli (Comps.), Paisajes y procesos sociales en Tafi del Valle, (pp. 79-94). Tucumán: Imprenta de la Universidad Nacional de Tucumán.

"Carbonelli, J. P. (2009). Interacciones cotidianas entre materias primas y sujetos sociales en el Valle de Yocavil. El caso del sitio Soria 2 (Andalhuala, Pcia. de Catamarca). (Tesis de Licenciatura inédita), Universidad de Buenos Aires, Argentina.

"Carbonelli, J. P. (2011). "Motivos porque y para" en la tecnología lítica de un sitio formativo en el Valle de Yocavil. Intersecciones en Antropología, 12, 31-44.

"Carbonelli, J. P. (2012). Secuencia de producción lítica en el sitio Mesada del agua salada, Caspinchango, Valle de Yocavil. Revista Española de Antropología Americana, 42(2), 359-382.

" Caria, M., Escola, P., Gómez Augier, J. P. y Glascock, M. (2009). Obsidian Circulation: new spaces of spread for the Northwest of Argentina. International Association for Obsidian Studies Bulletin, 40, 5-11.

" Cigliano, E. (1960). Investigaciones arqueológicas en el Valle de Santa María. Publicación, 4, 7-12.

" Cigliano, E. (1961). Noticia sobre una Nueva Industria Precerámica en el Valle de Santa María (Catamarca): El Ampajanguense. Anales de Arqueología y Etnología, Sección Arqueología, XVI, 169-179.

" Cigliano, E. (1962). El Ampajanguense. Publicación 5 del Instituto de Antropología. Rosario: Facultad de Filosofía y Letras.

"Cigliano, E. (1968). Panorama General de las Industrias Precerámicas en el Noroeste Argentino. Actas y Memorias XXXVII Congreso Internacional de Americanistas, Tomo III, p. 339-344. Buenos Aires.

" Chiappe Sánchez, N. R. (2007). Sobre la construcción social de la muerte. Las prácticas funerarias en un sitio agroalfarero temprano: Bajo Los Cardones -Amaicha del Valle, Tucumán. (Tesis de licenciatura inédita), Universidad Nacional de Tucumán, Argentina.

"Church, T. (1994). Lithic Resource Studies: a Sourcebook for Archaeologists. Tulsa: Department of Anthropology, University of Tulsa. 
"Ericson, J. (1984). Toward the analysis of lithic production systems. Prehistoric quarries and lithic production. En J. Ericson y B. Purdy (Eds.), Prehistoric quarries and lithic production (pp. 1-10). Cambridge: Cambridge University Press.

"Espinosa, S. (1995). Dr. School y Monsier Fleur: de talones y bulbos. Cuadernos del Instituto Nacional de Antropología y Pensamiento Latinoamericano, 16, 315-328.

» Gaál, E. y Carbonelli, J. P. (2012). Caracterización de las materias primas y la tecnología lítica del sitio formativo Soria 2, Andalhuala, provincia de Catamarca. En N. Kusperszmit, L. Mucciolo, T. Lagos Mármol y M. Sacchi (Eds.), Entre pasados y presentes III. Estudios contemporáneos en ciencias antropológicas (pp. 369-383). Buenos Aires: Fundación de Historia Natural Félix de Azara.

» García Salemi, M. y Durando, P. (1985). Sobre cronologías y paleoclimas en la quebrada de Amaicha. Revista CERS, 2(2), 45-57.

» García Salemi, M., Platanía, G. y Durando, P. (1988). Nuevos aportes al estudio de sitios arqueológicos superficiales acerámicos: barnices y cronologías relativas en el Valle de Santa María, Tucumán-Catamarca, República Argentina. Manuscrito inédito.

» Germano, F., Chávez, L., Medina Chueca, J., Martínez, S., Gómez Sánchez, M., Nieva, M., Navarro, P. y Somonte, C. (2007). Caracterización de un conjunto lítico en el sitio Bajo Los Cardones (Amaicha del Valle, Tucumán). Trabajo presentado en $2^{\circ}$ Congreso Argentino de Arqueometría y 1ํㅡㄴ Latinoaméricano de Arqueometría, Buenos Aires, Argentina.

» Gómez Augier, J. y Caria, M. (2012). Caracterización arquitectónica y espacial de los complejos habitacionales y productivos del sitio El Divisadero (Cumbres CalchaquiesTucumán). Comechingonia, 16, 105-127

» González, O. (1990). Las volcanitas del Portezuelo de las Ánimas, Sierra de Aconquija, Provincias de Catamarca y Tucumán. Revista de la Asociación Geológica Argentina, $\mathrm{XLV}(3-4), 386-396$.

" González, O. y Barreñada, O. (1993). Geología y estructura de las nacientes del río Amaicha y El Infiernillo, Provincia de Tucumán. Trabajo presentado en el XII Congreso Geológico Argentino y II Congreso de Exploración de Hidrocarburos, Mendoza, Argentina.

»Hocsman, S., Somonte, C., Babot, P., Martel, A. y Toselli, A. (2003). Análisis de materiales líticos de un sitio a cielo abierto del área valliserrana del NOA: Campo Blanco (Tucumán). Cuadernos del Instituto Nacional de Antropología y Pensamiento Latinoamericano, 20, 325350.

» Lazzari, M. (1998). La economía más allá de la subsistencia: Intercambio y producción lítica en el Aconquija. Arqueología, 7, 9-49.

» Martínez, J., Mauri, E., Mercuri, C., Caria, M. y Oliszewski, N. (2013). Mid-Holocene human occupations in Tucumán (northwest Argentina). Quaternary International, 307, 86-95.

» Nami, H. (1992). El subsistema tecnológico de la confección de instrumentos líticos y la explotación de los recursos del ambiente: una nueva vía de aproximación. Shincal, 2, 33-53.

» Oliszewski, N. (2011). Ocupaciones prehispánicas en la Quebrada de los Corrales, El Infiernillo, Tucumán (ca. 2500- 6oo años AP). Comechingonia, 14, 155-172.

» Oliszewski, N., Caria, M. y Martínez, J. G. (2013). Aporte a la arqueología del noroeste de Argentina: El caso de la Quebrada de los Corrales (El Infiernillo, Tucumán). Materialidades. Perspectivas en cultura material, 1, 26-56.

» Oliszewski, N., Martínez, J. G. y Caria, M. (2008). Ocupaciones prehispánicas de altura: el caso de Cueva de los Corrales 1 (El Infiernillo, Tafí del Valle, Tucumán). Relaciones de la Sociedad Argentina de Antropología, XXXIII, 209-221. 
» Scattolin, C. y Lazzari, M. (1997). Tramando redes: Obsidianas al oeste del Aconquija. Estudios atacameños, 14, 189-209.

»Somonte, C. (2002). El uso del espacio y la producción y/o descarte de materiales líticos en la Quebrada de Amaicha del Valle, Pcia. de Tucumán. (Tesis de Licenciatura inédita), Universidad Nacional de Tucumán, Argentina.

»Somonte, C. (2005). Uso del espacio y producción lítica en Amaicha del Valle, dpto. Tafí del Valle, Tucumán. Intersecciones en Antropología, 6, 3-19.

»Somonte, C. (2007). Espacios persistentes y producción lítica en Amaicha del Valle, Tucumán. En P. Arenas, B. Manase y E. Noli (Comp.), Paisajes y procesos sociales en Tafí del Valle. (pp. 47-78). Tucumán: Imprenta de la Universidad Nacional de Tucumán.

»Somonte, C. (2009). Tecnología Lítica en Espacios Persistentes de Amaicha del Valle (Tucumán). (Tesis Doctoral inédita), Universidad de Buenos Aires, Argentina.

»Somonte, C. y Baied, C. (2011). Recursos líticos, aprovisionamiento y aspectos temporales de fuentes de abastecimiento en Amaicha del Valle, Tucumán, Argentina. Comechingonia, 14, 97-113.

»Somonte, C. y Baied, C. (2013). Edad mínima de exposición de superficies en canteras taller: Reflexiones en torno a las primeras dataciones mediante microlaminaciones del barniz de las rocas (VML) para el Noroeste Argentino. Chungara. Revista de Antropología Chilena, 45(3), 427-445.

»Somonte, C., Hocsman, S., Martel, A. y Babot, P. (2004). Procesos de formación en un sitio cantera-Taller: Campo Blanco (Tucumán, Argentina). Chungara. Revista de Antropología Chilena, 36(2), 983-995.

»Sullivan, A. y Rozen, K. (1985). Debitage analysis and archaeological interpretation. American Antiquity, 50, 755-779.

» Torrence, R. (1989). Re-tooling: towards a behavioral theory of stone tools. En R. Torrence (Ed.), Time, Energy and Stone Tools (pp. 57-66). Cambridge: Cambridge University Press. 